\title{
Research on Evaluation of Cloud Service Providers for Small and Medium Enterprises in the Smart City
}

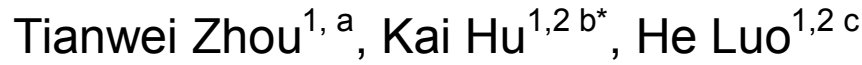 \\ ${ }^{1}$ School of Management, Hefei University of Technology Hefei, Anhui Province, China \\ ${ }^{2}$ Key Laboratory of the Ministry of Education on Process Optimization \& Intelligent Decision Making, \\ Hefei, Anhui Province, China \\ atlztw@sina.com, ${ }^{b}$ hfuthukai@163.com,
}

Keywords: cloud service providers; Small\&Medium enterprises; index system; Analytic Hierarchy Process; smart city

\begin{abstract}
- the evaluation index system of selecting cloud service providers is proposed according to the informational requirements of Small and Medium enterprises in the smart city and the characteristics of cloud services. The corresponding index system is suggested from three aspects which include the strength of cloud service providers, cloud service security and performance of cloud service system. The weights of indexes are calculated using the AHP (Analytic Hierarchy Process) method, and numerical example is also given to verify the effect.
\end{abstract}

\section{Introduction}

The smart city is to realize intelligent management, comprehensive monitoring, and sustainable development for human beings using a sort of new technologies, such as cloud computing, big data, internet of things, and so on [1-3]. The Small and Medium Enterprises (SMEs) is one of the most important roles during the process of building smart city. As an important part of the national economy, SMEs have occupied $99 \%$ of the total enterprises, created $60 \%$ of the national industrial output and $40 \%$ of the tax. But SMEs are usually small economic units, compared with large enterprises industry in personnel scale, assets scale and operation scale. The enterprise staff, sales, total assets and other indicators are also defined for the SME [4].

In recent years, information construction has gradually become one of the key aspects in the process of building smart city. In terms of infrastructure, the access rate of network has reached $90 \%$ [3]. However, due to the limitation of finance and human resource, SMEs are facing many difficulties with the smart city, such as the long project development cycle, the deployment of high risks, cost of inputs, lacking of professional information technology and so on.

In the smart city, cloud computing technology provides a new mode of information construction for SMEs. Cloud service providers can provide users with the services they needed in the way of on-demand payment by using the virtual service resources. For example, data storages, network bandwidth, system platforms, application software can be virtualized as a kind of service. This cloud computing service pattern can provide a convenient information environment for SMEs, and eliminate multifarious works in the process of information management. At the same time, it can also save the cost of purchasing, using, maintaining hardware and software. Therefore, cloud service providers has been concerned by more and more SMEs [5].

However, the existing cloud service pattern cannot be copied or applied directly from others because of the difference of the products. Every SME should choose an appropriate cloud service provider and corresponding cloud service according to the characteristics of its situation. In order to realize this choice, Fuzzy set method is put forward by Weiwen $\mathrm{Wu}$ [6] to explore the important factors which influence the selection of cloud computing services. It can facilitate cloud services providers to gain customers' demand, and attract more customers; Sangjae Lee [7] proposed the balanced scorecard (BSC) to evaluate cloud computing services, which include four indicators: learning and growth, internal business processes, customer performance and financial performance; 
Javier Espadas[8] established a formal evaluation way of virtualization resources which are deployed in the cloud computing infrastructure.

However, the evaluation methods mainly focused on the quality of services but lack of the capacity of the cloud service providers. A comprehensive and objective evaluation index of the cloud service provider is suggested in this paper based on the analysis of the existing evaluation index, and the AHP is also used to calculate the weights of each indicator. Then the index system for evaluating cloud service provider of the SME in smart city is proposed.

\section{The index system of selecting cloud service providers for SMEs}

Considering the needs of customers of SMEs and the characteristics of cloud service providers based on the literature research, we can get alternative evaluation indexes of selecting cloud service providers for SMEs. Finally we get three aspects with 20 indexes shown in Table 1.

Table 1. The index system of selecting cloud service providers for SMEs

\begin{tabular}{|c|c|c|}
\hline Criterion & & Index \\
\hline \multirow{6}{*}{$\begin{array}{c}\text { The strength of cloud } \\
\text { service providers } \\
\text { A1 }\end{array}$} & B1 & Degree of team perfection \\
\hline & $\mathrm{B} 2$ & Quality of latter-phase services \\
\hline & B3 & Quality of cloud service \\
\hline & B4 & Financial status \\
\hline & B5 & Capability of research and development \\
\hline & B6 & Cost of cloud services \\
\hline \multirow{7}{*}{$\begin{array}{l}\text { Cloud service security } \\
\text { A2 }\end{array}$} & B7 & Infrastructure security \\
\hline & B8 & Network communications security \\
\hline & B9 & Safeguards \\
\hline & $\mathrm{B} 10$ & Safety management system \\
\hline & B11 & Data security of cloud storage \\
\hline & B12 & Integrity of virus prevention \\
\hline & B13 & Protection of power outages \\
\hline \multirow{7}{*}{$\begin{array}{l}\text { Performance of cloud } \\
\text { service system } \\
\text { A3 }\end{array}$} & B14 & Stability \\
\hline & B15 & Length of deployment cycle \\
\hline & B16 & Flexibility of choosing business \\
\hline & B17 & Changeability of business \\
\hline & B18 & Flexible.in the process of dealing \\
\hline & B19 & Application integration \\
\hline & B20 & Scalability \\
\hline
\end{tabular}

\section{A. the Strength of Cloud Service Providers}

As an enterprise, cloud service provider must have certain human, financial and other resources in order to ensure the normal operation of enterprise. Therefore, the degree of team perfection, capability of research and development and financial status these three indexes should be taken into account in the evaluation index set when SMEs select cloud service providers.

The degree of customers' affection to the product is directly affected by the quality of cloud service and latter-phase services. However, SMEs are limited by fund. They not only expect to get a higher quality of cloud services, but a more reasonable cost of cloud services. Therefore, the quality of cloud services, the quality of latter-phase services and the cost of cloud services should be included in the criteria of the strength of cloud service providers.

\section{B. Cloud Service Security}

It would increase the possibility of leakage of user information which stored in the equipment of the service provider when SMEs get the services from the cloud service providers, thus requiring the cloud providers must have higher security in information management. Good Infrastructure is the 
primary condition of information management and uninterrupted power supply will avoid the happening of power outages.

At the same time, it's necessary for cloud service providers to establish the safe management system and safeguards for the safety and efficiency of information management activities. Besides, it's also very important to consider that how to avoid the leakage of data in the process of storage and transmission. Therefore, the network communications security, the data security of cloud storage and integrity of virus prevention functional these three indexes should be included in the criteria of the cloud service security.

\section{Performance of Cloud Service System}

Superior performance of cloud service system reflect the high quality of cloud services. SMEs need to deploy business processes on the cloud service system, which require cloud services to maintain high stability in the course of running the system. In addition, they also want a cloud service system with better availability to be more flexible in the process of dealing data.

Cloud service system in the process of implementation needs to integrate with existing systems for SMEs user's application, which can make a smooth transition of business processes. With the development of business and information technology, other service systems or modules may be adopted by SMEs customers, which require cloud service system to have better scalability.

In the process of implementing cloud services system, SMEs customers want more flexibility to choose the service module and change business requirements, which enables the system to suit the corporate status and requirements better. In addition, users expect cloud services can bring benefits for the enterprise as soon as possible, which requires the time for implementing cloud services system as short as possible. Therefore, evaluation indexes should include flexibility of choosing business module, changeability of business requirements and length of deployment cycle.

\section{Define the evaluation index weights of cloud service provider}

\section{A. the principles and procedures of establishing index weights}

Analytic Hierarchy Process (AHP) is used to define weights according to evaluation indexes of cloud service providers which selected by SMEs users. AHP is a method combined quantitative analysis with qualitative analysis which often divides decision-making indexes into objectives layer, Criterion layer, indexes layer. This method offers an easy approach to solve complex decision problems by using quantitative information to make the decision-making process numerical. So as to obtain the rank of importance of all decision factors relative to overall evaluation objectives, we build a judgment matrix according to pairwise comparisons between hierarchical internal factors. The steps are as follows:

Step 1 Define the comparative judgment matrix between any two indexes.

This paper adopts the scoring criteria of Satty [10] using 1- 9 grades to represent the importance of the ratio of any two elements (Table 2).

According to the relative importance of comparison between the elements, it can obtain a pairwise comparison judgment matrix A, where $a_{i j}$ is the importance score of element $i$ relative to element $j$.

$$
A=\left(a_{i j}\right)_{n \times n}
$$

Step 2 Deal with judgment matrix by normalization and calculate the maximum eigenvectors.

Applying formula (2) to obtain normalized judgment matrix and formula (3) to obtain the maximum eigenvector.

$$
w_{i}=\frac{\left(\prod_{j=1}^{n} a_{i j}\right)^{\frac{1}{n}}}{\sum_{k=1}^{n}\left(\prod_{j=1}^{n} a_{k j}\right)^{\frac{1}{n}}}
$$




$$
\lambda_{\max }=\frac{1}{n} \sum_{i=1}^{n} \frac{\sum_{j=1}^{n} a_{i j} w_{j}}{w_{i}}
$$

Table 2. Satty scoring criteria

\begin{tabular}{|c|c|}
\hline Scale & Mean \\
\hline 1 & It represents that they have the same importance when compare to two elements. \\
\hline 3 & It represents that the former has moderate importance when compare to two elements. \\
\hline 5 & It represents that the former has strong importance when compare to two elements. \\
\hline 7 & $\begin{array}{l}\text { It represents that the former has demonstrated importance when compare to two } \\
\text { elements. }\end{array}$ \\
\hline 9 & It represents that the former has extreme importance when compare to two elements. \\
\hline $2,4,6,8$ & It represents an intermediate value of the adjacent determination. \\
\hline Reciprocal & $\begin{array}{l}\text { If the ratio of the importance of the element } i \text { and } j \text { is } a_{i j} \text {, the ratio of the } \\
\text { importance of the element } j \text { and } i \text { is } a_{i j}=1 / a_{j i}\end{array}$ \\
\hline
\end{tabular}

Step 3 Check for consistency, calculate test coefficient CR and consistency index CI

$$
\left\{\begin{array}{l}
C I=\left(\lambda_{\max }-n\right) /(n-1) \\
C R=C I / R I
\end{array}\right.
$$

Formula (4) is used to calculate $\mathrm{CR}$ and $\mathrm{CI}$ where $\mathrm{n}$ is order of the matrix. CR is used to measure whether a different order judgment matrix has satisfactory consistency. If the value of CR is less than or equal to 0.1 , it can be considered that judgment matrix has satisfactory consistency, otherwise needed to re-adjust the judgment matrix. When $\mathrm{n}$ is less than or equal to 2 , it doesn 't need consistency check. For 1-8 order judgment matrix, the average random consistency index RI value of judgment matrix are as shown in Table 3.

Table 3. The value of 1-8 order random consistency index RI

\begin{tabular}{|c|c|c|c|c|c|c|c|c|}
\hline Order & 1 & 2 & 3 & 4 & 5 & 6 & 7 & 8 \\
\hline$R I$ & 0.00 & 0.00 & 0.58 & 0.90 & 1.12 & 1.24 & 1.32 & 1.41 \\
\hline
\end{tabular}

\section{B. the evaluation Indexes weights calculation of cloud service providers}

Based on the discussion and evaluation about the importance between the three elements of the above criteria layer, finally we get a more consistent rating results, a judgment matrix A, which can get the result through compare the importance of the matrix of every two elements:

$$
A=\left(\begin{array}{ccc}
1 & 1 / 3 & 2 \\
3 & 1 & 4 \\
1 / 2 & 1 / 4 & 1
\end{array}\right)
$$

We can get its maximum eigenvector $\lambda_{\max }=3.0183$, the normalized eigenvector $\overline{W_{A}}=(0.2385,0.6250,0.1365)^{T}$ and $C R=0.0158<0.1$, which have pass the consistency check.

Comparing two indexes of each criteria layer, we can get the scores, the criteria layer's judgment matrixes, weights, characteristic value, test coefficient and other data. The results are as follows: 
The indexes $(B 1-B 6)$ of the strength of cloud service providers, $\overline{W_{B 1-B 6}}=$ $(0.065,0.1733,0.3850,0.1071,0.2267,0.0430)^{T}, \lambda_{\max }=6.3835, C R=0.0609<0.1$, pass the consistency check.

The indexes $(B 7-B 13)$ of the strength of cloud service providers, $\overline{W_{B 7-B 13}}=$ $(0.3517,0.1596,0.0678,0.0449,0.2412,0.1040,0.0308)^{T}, \lambda_{\max }=7.1950, C R=0.0239<0.1$, pass the consistency check.

The indexes $(B 14-B 20)$ of the strength of cloud service providers, $\overline{W_{B 14-B 20}}=$ $(0.3517,0.0678,0.1596,0.2412,0.1040,0.0449,0.0308)^{T}, \lambda_{\max }=6.3835, C R=0.0609<0.1$, pass the consistency check.

The specific indexes weights are as shown in table 4.

Table 4 The weights of index system of selecting cloud service providers for SMEs

\begin{tabular}{|c|c|c|}
\hline Criterion & Index & Weight \\
\hline & Degree of team perfection & 0.0155 \\
\hline \multirow{5}{*}{$\begin{array}{l}\text { The strength of } \\
\text { cloud service } \\
\text { providers } \\
\text { A1 }\end{array}$} & Quality of latter-phase services & 0.0413 \\
\hline & Quality of cloud service & 0.0918 \\
\hline & Financial status & 0.0256 \\
\hline & Capability of research and development & 0.0540 \\
\hline & Cost of cloud services & 0.0103 \\
\hline \multirow{7}{*}{$\begin{array}{c}\text { Cloud service } \\
\text { security } \\
\text { A2 }\end{array}$} & Infrastructure security & 0.2198 \\
\hline & Network communications security & 0.0998 \\
\hline & B9 $\quad$ Safeguards & 0.0424 \\
\hline & B10 $\quad$ Safety management system & 0.0281 \\
\hline & B11 Data security of cloud storage & 0.1507 \\
\hline & B12 Integrity of virus prevention & 0.0650 \\
\hline & B13 Protection of power outages & 0.0192 \\
\hline \multirow{7}{*}{$\begin{array}{l}\text { Performance of } \\
\text { cloud service } \\
\text { system } \\
\text { A3 }\end{array}$} & B14 Stability & 0.0480 \\
\hline & B15 Length of deployment cycle & 0.0093 \\
\hline & B16 Flexibility of choosing business & 0.0218 \\
\hline & B17 Changeability of business & 0.0329 \\
\hline & B18 Flexible.in the process of dealing & 0.0142 \\
\hline & B19 Application integration & 0.0061 \\
\hline & B20 Scalability & 0.0042 \\
\hline
\end{tabular}

From the result of the criteria layer indexes, cloud service security and the strength of cloud service providers obtain respectively the weight of 0.6250 and 0.2385 , the performance of cloud service system obtain the weight of 0.1365 , which measure up the principle of the fact that SMEs users always put the strength of cloud service providers and cloud service security at important positions in the process of evaluating cloud service providers.

From table 4, important indexes of the criteria layer of cloud service security including infrastructure security $(0.2198)$, data security of cloud storage $(0.1507)$, network communications security (0.0998) and so on, these indexes are mainly concentrated in information security management, which is consistent with the factors to be considered that SMEs users put their information in the cloud service provider's equipment. The most important index in the criteria layer of the strength of cloud service providers is the quality of cloud service (0.0918), which is also must be considered when SMEs users choosing cloud service providers. In addition, in practice, users expect cloud service providers can meet the demand of SMEs in changeability of business requirements and the choice of business module. Changeability of business requirements (0.0329) 
and flexibility of choosing business module (0.0218) in the criterion layer of performance of cloud service system also won a larger weight.

From the table above, we can use the AHP method to calculate the weights of each index elements. The result is shown as follows:

$$
\begin{aligned}
& U=(0.0155,0.0413,0.0918,0.0256,0.0540,0.0103,0.2198,0.0998,0.0424,0.0281,0.1507,0.0650, \\
& 0.0192,0.0480,0.0093,0.0218,0.0329,0.0142,0.0061,0.0042)
\end{aligned}
$$

Supposing the evaluation value vector of element is $X=\left(x_{1}, x_{2}, \cdots x_{n}\right)$, the weight vector of index element is $U=\left(u_{1}, u_{2}, \cdots u_{n}\right)$, we can get the third party credibility value computation formula, shown as follows:

$$
T=X \times U=\left(x_{1}, x_{2}, \cdots x_{n}\right) \times\left(u_{1}, u_{2}, \cdots u_{n}\right)^{T}=\sum_{i=1}^{n} x_{i} u_{i}
$$

For example, suppose that there are three cloud service providers that can afford the cloud services for SMEs, and represent it as A, B and C respectively, Through scoring of expert and scientific computing, using the above method and model to analyze and evaluate their credibility, we can get the value of every index elements respectively. The values are as follows:

$X_{1}=(0.90,0.85,0.82,0.90,0.88,0.80,0.78,0.84,0.81,0.76,0.77,0.88,0.95,0.85,0.85,0.88,0.91,0.84$

$, 0.79,0.82)$

$X_{2}=(0.96,0.98,0.88,0.85,0.86,0.79,0.88,0.88,0.86,0.92,0.96,0.78,0.85,0.93,0.95,0.86,0.83,0.88$

$, 0.80,0.82)$

$X_{3}=(0.88,0.89,0.92,0.82,0.90,0.82,0.79,0.94,0.88,0.85,0.92,0.78,0.90,0.75,0.77,0.82,0.91,0.82$

$, 0.85,0.87)$

Put these values into formula (5), we can get the value of $T$.

$$
\begin{aligned}
& T_{1}=X_{1} \times U_{1}=\left(x_{1}, x_{2}, \cdots x_{20}\right) \times\left(u_{1}, u_{2}, \cdots u_{20}\right)^{T}=\sum_{i=1}^{20} x_{i} u_{i}=0.823605, \\
& T_{2}=X_{2} \times U_{2}==0.888081, \\
& T_{3}=X_{3} \times U_{3}==0.859625 .
\end{aligned}
$$

Finally, we can get the result $T_{2}>T_{3}>T_{1}$.

According to the above results, we should choose B as cloud service providers. We can find it is better than others in quality of cloud service, data security of cloud storage, flexibility of choosing business module and so on. And the value of credibility calculated is highest.

\section{Conclusion}

The indicator system is proposed in this paper according to the requirement from SME, it can not only be used as the reference standard for users choosing a cloud service provider, but also provide support decision for decision makers. The characteristics of cloud service are considered in this indicator system, and the AHP is also applied in the indicator system to calculate the weight of each index. When SMEs evaluate cloud service providers, they should combine the other indicators of the cloud services, and consider the security of information management as a primary factor. They should also to ensure that cloud service providers can offer highly security services and rich resources for SMEs. 


\section{Acknowledgments}

This work was partly supported by the National Natural Science Foundation of China (nos. 71401048, 71201042, 71131002), Anhui Provincial Natural Science Foundation (1508085MG140) and the Humanities and Social Science Projects of Ministry of Education of China (no. 13YJC630051).

\section{References}

[1] Sotirios Paroutis, Mark Bennett, Loizos Heracleous. A strategic view on smart city technology: The case of IBM Smarter Cities [J]. 2014, 89, 262-272.

[2] Soumaya Ben Letaifa. How to strategize smart cities: Revealing the SMART model [J]. Journal of Business Research. 2015, 68(7): 1414- 1419.

[3] Paolo Neirotti, Alberto De Marco, Anna Corinna Cagliano, Giulio Mangano, Francesco Scorrano. Current trends in Smart City initiatives: Some stylised facts [J]. Cities. 2014, 38, 25-36.

[4] Katharina Laufs, Christian Schwens. Foreign market entry mode choice of small and medium-sized enterprises: A systematic review and future research agenda [J]. International Business Review. 2014, 23(6): 1109-1126.

[5] Prashant Gupta, A. Seetharaman, John Rudolph Raj. Prashant Gupta, A. Seetharaman, John Rudolph Raj [J]. International Journal of Information Management. 2013, 33(5): 861-874

[6] Wei-Wen Wu. Mining significant factors affecting the adoption of SaaS using the rough set approach [J]. The Journal of Systems and Software, 2011, 84:435-441.

[7] Lee S, Park S B, Lim G G. Using balanced scorecards for the evaluation of "Software-as-a-service" [J]. Information \& Management, 2013, 50(7): 553-561.

[8] Javier Espadas, Arturo Molina, Guillermo Jimenez. A tenant-based resource allocation model for scaling Software-as-a-Service applications over cloud computing infrastructures [J]. Future Generation Computer Systems, 29(2013): 273-286.

[9] Saaty T L, Erdener E. A New Approach to Performance Measurement: the Analytic Hierarchy Process [J]. Design Methods and Theories, 1979, 13(2).

[10] Saaty T L. Decision Making with Dependence and Feedback: the Analytic Network Process [M]. Pittsburgh: RWS Publications, 2001. 